\title{
Prevalence of Risk Factors of Non-Communicable Diseases amongst Female Prisoners of Pakistan
}

\author{
Salina Mukhtar ${ }^{1}$, Atif Mahmood ${ }^{2}$, Asima Faisal ${ }^{3}$, Saima Ejaz ${ }^{4}$, Fahmida \\ Khatoon $^{5}$ \\ ${ }^{1}$ Product Manager, Sanofi Aventis, Pakistan, \\ ${ }^{2}$ Department of Physiology, Shaheed Mohtarma Benazir Bhutto Medical College, Karachi, Pakistan, \\ ${ }^{3}$ Institute of Business Management, Karachi, Pakistan, \\ ${ }^{4}$ Department of Physiology, Dow University of Health Sciences, Karachi, Pakistan, \\ ${ }^{5}$ Department of Biochemistry, United Medical and Dental College, Karachi, Pakistan
}

\begin{abstract}
Objective: To determine the prevalence and the differences in the prevalence of risk factors for noncommunicable diseases among the female prisoners of all four provinces of Pakistan.

Method: Cross-sectional study which was conducted at the Female Prison of Karachi (Sindh), Koth Lakh Patt (Punjab), Quetta (Baluchistan) and Haripur Jail (Khyber Pakhtoon Khuwah). Sample size was determined by the rule of thumb and 269 adult female prisoners of all the four Prisons (66\% population of each prison) were recruited, thereby, determining one prison of each province of Pakistan, the age of whom ranged from 16 years and onwards. The blood pressure, random blood sugar and anthropometric measurements including height, weight, BMI and waist hip circumference of the prisoners were performed.

Result: Among the female prisoners of Pakistan, $71 \%$ belonged to Pakistani origin, while 23\% (n=61) were foreigners. Amongst the foreigners, 79\% belonged to African countries e.g. Nigeria, Guinea etc. Among the female prisoners, $24.9 \%$ were smokers of whom $5 \%$ smoked a maximum of 40 cigarettes per day. Majority of these prisoners (75.4\%) had no access to fruits. Vegetable oil consumption was found in $39 \%$ prisoners while $44.2 \%$ used ghee, $16.3 \%$ were not sure about the type of oil used in their meals. A significance difference was observed in the type of oil consumed in meals in all the four prisons visited $(p<0.01)$. Among the subjects, $55 \%$ were satisfied with the food that they get. The mean BMI assessed was 36.63, $1.57 \mathrm{~m}$ is the mean height, and 67 $\mathrm{kg}$ is the mean weight. $46.5 \%$ females were found to have a normal BMI, 26.4\% were over-weight, while $27.13 \%$ were found to be obese.

Conclusion: The prevalence of risk factor of Non-communicable diseases in the female prisoners of Pakistan was found to be high. There was a higher incidence of smoking amongst the female prisoners than the normal female population of Pakistan. The dietary habits and less use of Fruits were seen in all the four prisons, thereby, increasing the risk of having Non-communicable diseases
\end{abstract}

Keywords: Prevalence; Non-Communicable diseases; Risk factors; Pakistani Female Prisoners; Prevalence.

\section{Introduction:}

By the dawn of 3rd Millennium, Non-Communicable Diseases are sweeping the entire globe. ${ }^{[1]}$ The major point of concern in the world is the increasing trend of Non-communicable diseases in developing countries. By 2020, it is predicted that these diseases will be causing 7 out of 10 deaths in developing countries. ${ }^{[2]}$ With the growing trend of Non-Communicable diseases, the World is also facing an increase in the risk factors of NCDs. ${ }^{[1]}$

With the changing global trends, risk factors associated with NCDs e.g. Blood Pressure, Cholesterol, Tobacco, Alcohol, Obesity now dominate developing countries as well where they create a double burden on top of infectious diseases. ${ }^{[1]}$

The number of female prisoners is rising in countries all over the world, resulting in over-crowding of Female Prisons \& other detention facilities. Increasing levels of over-crowding is one of the many things compounding the substandard conditions of prisons. Inadequate living space, poor or non-existent Ventilation, limited sanitation facilities, low levels of cleanliness \& hygiene and inadequate food \& medical supplies makes female prison life-threatening in many countries. While conditions of detention vary greatly from country to country \& facility-to-facility; standards in most countries are shockingly low. ${ }^{[3]}$

As far as Health facilities are concerned, the prison authorities in many countries failed to provide basic needs to Female prisoners. Health care in most of the Female prisons are poor to non-existent. Even in developed countries, Medical services for Female prisoners are often seriously inadequate. The insufficient food or poor diet ultimately leads to increasing prevalence of malnutrition, semi starvation \& death. This problem is seen in many countries around the World, of them, some are: Angola, Armenia, Azerbaijan, Burundi, 
Cambodia, Columbia, Cuba, Ethiopia, Haiti, Mexico, Mozambique, Peru, Russia, Tajikistan, Tanzania, Turkmenistan, Uganda, Uzbekistan and Pakistan. ${ }^{[4]}$

According to HRCP, there are 80,000 prisoners in jails that were built to hold a maximum of 35,833 persons. According to The Progressive Women's Association, there were approximately 2.76 female prisoners in jails nationwide at the end of 2002. Although, special female prisons have been established nationwide, but these prison receive fewer material \& human resources than regular Prisons. Efforts to raise funds for these Prisons achieved minimal results. In the prison, of all the various types of deprivation women are facing, of particular concern, is the lack of Health care services in female prison. Inadequate supply of food in female prison of Pakistan has led to chronic malnutrition for those unable to supplement their diet \& help from family $\&$ friends. Excess to medical care is a big problem. ${ }^{[5]}$

Nutritional trends are undergoing worldwide change. Obesity in adults leading to its morbidities is increasing even in developing countries including Pakistan. This research is primarily meant to access the risk factors of Non-communicable diseases among the Female inmates. Prisoners are unique captured population who are at increased risk of both communicable \& non-communicable diseases. This study will find out the risk factors of Non-communicable diseases among female inmates at the four Prisons of Pakistan, one on each province to assess the differences in each prison and also to maintain the uniformity of the study.

\section{Patients and Methods:}

The study design used in this study is Cross-Sectional Survey

In order to get a uniform sample of Female Prisoners of Pakistan, the study was conducted on one female prison of each of the 4 provinces of Pakistan. Therefore, the study site was:

- Female Prison, Central Jail, Sindh

- Female Prison, Punjab

- Female Prison, Khyber Pakhtoon Khuwah

- Female Prison, Baluchistan

All those females who are registered as the female adult Prisoners \&Those adult female prisoners who gave consent to participate in the research work were included in the research

Disabled female adult prisoners and all those female adult prisoners who have been enrolled in the prison within the recent 3 months were excluded from the research.

The sample for the study included 66\% Female adult prisoners of each Prison visited in each province. The age of the population ranged from $16 \&$ above. The sample size was taken on the basis of rule of thumb as used by other studies done on the similar topics. The sample population was taken by Non-probability, Purposive sampling technique.

The data was collected by visiting the four prisons of Pakistan, one of each province. A written consent was read out to each prisoner before the start of the interview. The interview was taken from each prisoner and questions were asked, based on the pre-written \& translated WHO-STEPS questionnaire. Specific measurements to determine the BMI of each prisoner (e.g. Height \& Weight) were taken at the end of the interview.

A WHO-based questionnaire was used. The questionnaire was a STEPS instrument for Noncommunicable diseases risk factors. STEPS is a WHO program for Stepwise approach to surveillance of Noncommunicable diseases. The WHO-based Questionnaire was modified by translating the questionnaire in Urdu for the convenience of the Female Prisoners. During Data analysis, the questionnaire was retranslated back to English.

The data was collected by visiting the concerned prisons of each province. A written consent was read out to each prisoner before the start of the interview. The interview was taken from each prisoner and questions were asked based on the pre-written \& translated WHO STEPS questionnaire. Specific measurements to determine the BMI of each prisoner (e.g. Height \& Weight) were taken at the end of the interview. SPSS Program Version 17.for the data entry and statistical analysis will be used during the study.

\subsection{Socioeconomic and Demographic Analysis}

\section{Results:}

A total of 269 female inmates of Pakistan were surveyed. The sample was taken from each prison of each province of Pakistan. The 269 female inmates comprised of 114 prisoners of Central Jail, Karachi denoting the province of Sindh, 73 inmates of Koth Lakh Path, Lahore, representing the province of Punjab; 66 female Prisoners of the Central Jail, Quetta, depicting the province of Baluchistan \& 16 prisoners of Haripur Jail, denoting the province of Khyber Pakhtoon Khuwah. During the study period and the data collected, the diversities amongst all the 4 prisons of each province were observed. 
Out of the 269 female inmates who were included in the survey, $77.3 \%(n=208)$ were found to be Pakistani nationals. The remaining $22.7 \%$ ( $\mathrm{n}=61$ ) were found to be foreigners. (Figure I)

Amongst the foreign inmates, $63.8 \%$ belonged to Nigeria $(\mathrm{n}=39)$. The remaining foreigners include $15.5 \%$ belonging to Guinea $(n=9)$ while India, Bangladesh and Thailand each comprised of $6.89 \%$ of the total foreign prisoners $(\mathrm{n}=13)$.

About $68.40 \%$ of the female inmates belonged to age between 26 and 45 years $(n=184) ; 20.40 \%$ belonged to age ranging from 46 to 60 years $(\mathrm{n}=55)$; about $9.30 \%$ females belonged to the age group ranging from $16-25$ years $(n=25)$ while $1.85 \%$ females belonged to age greater than 60 years $(n=5)$

The mean age of our sample $(\mathrm{n}=269)$ was 35.44 years with standard deviation of 12.23 years. Most of the female inmates $(78.4 \%)$ belonged to reproductive age group that is $16-45$ years of age with the mean age of 32 years (SD +/- 7.00 years).

The educational status of the female inmates was also assessed during the survey. Majority of the respondents in our sample which comprised of about $46.4 \%$ did not have any formal schooling $(n=125)$. Approximately $31.6 \%$ did not complete their primary education $(\mathrm{n}=85)$. About $7 \%$ did complete their primary education $(\mathrm{n}=19), 11 \%$ of the female inmates were found to have completed their secondary education $(\mathrm{n}=29)$, while $4 \%$ had done their post-graduation and completed their university education $(\mathrm{n}=11)$ (FigureII).

\subsection{Descriptive Analysis:}

\subsubsection{Smoking Status}

Amongst the female inmates, about $24.9 \%$ were current smokers $(n=67)$. The youngest age at which the smoking was taken up by the female inmate was 10 years.

Amongst the daily smokers, $18 \%$ of female inmates smoked $1-4$ cigarettes/day $(\mathrm{n}=48)$; about $49 \%$ prisoners smoked 5-10 cigarettes daily $(\mathrm{n}=132) ; 12 \%$ female prisoners smoked $11-15$ cigarettes daily $(\mathrm{n}=32)$ while $16 \%$ smoked $15-20$ cigarettes daily $(n=43)$. (Table 1$) 5 \%$ prisoners smoked cigarettes greater than 20 each day $(n=13)$. The maximum number of cigarettes used daily was 40 . Out of the total prisoners who were smokers $(n=67), 87.5 \%$ were using manufactured cigarettes $(n=57)$, while the remaining smokers $(n=10)$, smoked handmade cigarettes e.g. Biiri and Huqqa.

\subsubsection{Fruit Intake}

Amongst all the female inmates, majority of the females, approx. $75.4 \%$ were those who had no access to fruits in a typical week $(n=203)$; about $17.4 \%$ had fruits $1-3$ servings a week $(n=47)$, while $7.2 \%$ had fruits servings for 5 and more days a week $(n=19)$. (Table 1) Most of the inmates who had access to fruits were foreigners.

\subsubsection{Oil Consumption}

The consumption of vegetable oil amongst the female inmates of Pakistan was found to be 39\% ( $\mathrm{n}=106) ; 44.2 \%$ were using butter or ghee in cooking $(n=119)$, while $16.3 \%$ were unaware of the type of oil consumed for their meal preparation $(\mathrm{n}=44)$ (Table 1). All the female prisoners who were consuming ghee in the preparation of meals were cooking their own food, while majority of the inmates who were having meal prepared in vegetable oil were consuming the Jail food provided by the government of Pakistan.

\subsubsection{BMI}

The mean height when measured was found to be $1.57 \mathrm{~m}(\mathrm{SD}=0.094 \mathrm{~m})$ while the mean weight was $67 \mathrm{Kg}(\mathrm{SD}=14.63 \mathrm{Kg})$. The mean BMI was $26.63(\mathrm{SD}=5.3)(\mathrm{n}=269)$.

Minimum BMI measured was 17.6 and maximum BMI measured was 43.15.Amongst the female inmates, 46.5\% females had normal BMI ranging from 19-24.9 $(\mathrm{n}=125)$; $26.4 \%$ were found to be over-weight with a BMI ranging from 25-29.9 $(n=71)$ while $27.13 \%$ were obese having a BMI of more than or equal to $30(n=73)$. (Table I)

\subsection{Comparative Analysis}

The Prevalence of risk factors of non-communicable diseases was analyzed amongst the female prisoners of each province. The difference in the risk factors between all the 4 prisons visited of each province was also assessed. (Table II)

Out of 269 female inmates who were interviewed during the survey, 72 were current smokers while 197 were non-smokers. Amongst the smokers, 30 belonged to Sindh; 19 were from Punjab; 18 belonged to Baluchistan while Khyber Pakhtoon Khuwah had 5 smokers. There was no significant difference in the smoking status between each province (Chi-Square; p-value: 0.97).

Amongst the overall population included in the research $(n=269), 49$ individuals were found to be taking Smokeless tobacco, which included mainly Gutka and Tobacco taken with Pan. Amongst those taking Smokeless tobacco, 15 female inmates were from Sindh; 18 from Punjab; 12 from Baluchistan; and 4 from 
Khyber Pakhtoon Khuwah. The difference in the intake of smokeless tobacco in between each province was found to be insignificant. (Chi-Square; p-value: 0.21).

The oil consumption was analyzed taking into account the usage of Ghee and Vegetable Oil. Amongst the female inmates of Pakistan ( $\mathrm{n}=269)$, 119 females were consuming Ghee in their meals; Vegetable oil was consumed by 106 individuals while 44 female inmates were not sure about the type of Oil used in the food they were consuming. In Sindh ( $\mathrm{n}=114), 10$ females were consuming Ghee; 79 had Vegetable oil in their meals while 25 were not sure about the type of Oil consumed by them. In Punjab ( $n=73), 59$ female inmates used Ghee in the preparation of their meals; 9 individuals were consuming Vegetable oil; and 5 were not sure. Baluchistan $(n=66)$ included 39 individuals who took Ghee in their meals; 16 individuals consuming vegetable oil while 11 prisoners were not sure about the type of Oil used in the preparation of their meals. In Khyber Pakhtoon Khuwah ( $\mathrm{n}=16), 11$ female prisoners used Ghee in the preparation of their meals; 2 individuals consumed Vegetable oil while 3 were not sure about the type of Oil they were consuming. There was a significant difference observed in the Oil consumption of the 4 provinces (ANOVA; $p$-value $<0.01$ ).

The dietary habits were also assessed amongst the female prisoners of Pakistan. Out of the total prisoners who were interviewed during the data collection $(n=269), 190$ individuals did not consume any fruit during their typical week; 59 prisoners consumed 1-4 servings of fruits in their typical week; while only 20 prisoners consumed more than 5 servings of fruits in their typical week. There was no significant difference found between the four prisons visited. (ANOVA; p-value: 0. 17).

The Body Mass Index was also calculated to evaluate the effect of the dietary habits on weight of the female prisoners. Amongst the female prisoners $(\mathrm{n}=269), 125$ individuals had a normal BMI, with their values ranging from 18-24.9; 71 females were found to be Over-weight with their BMI ranging from 25-29.9 while 73 female prisoners were found to be Obese with the BMI values greater than 30. None of the female prisoners were found to be underweight. Among those whose BMI was found to be normal ( $\mathrm{n}=125), 92$ prisoners belonged to Sindh; 18 were from Punjab; 12 females belonged to Baluchistan while 3 were from Khyber Pakhtoon Khuwah. Those females whose BMI denoted them to be Overweight $(n=71), 13$ were from Sindh; 23 from Punjab; 31 from Baluchistan while 4 were from Khyber Pakhtoon Khuwah. Amongst the Obese female prisoners, 9 belonged to Sindh; 32 to Punjab; 23 to Baluchistan while 9 were from Khyber Pakhtoon Khuwah. The BMI status of each prison was significantly different from each other (ANOVA; $p$-value $<0.01$ ).

\section{Discussion}

Nasir K. et al, with reference to regional differences and correlates to smoking, the highest prevalence were seen in the province of Sindh (16.1\%) and the lowest in North Western Frontier Province (7.1\%). ${ }^{[6]}$

Cropseya K. et al surveyed the female prisoners in Mississippi. The majority of female inmates $71.5 \%$ smoked cigarettes, with a mean of 14.6 cigarettes per day. ${ }^{[7]}$

Tracy L. et al examined the Prevalence of smoking among female arrestees of New York City. They found that $71 \%$ of all women were daily smokers. ${ }^{[8]}$

In our study, we found a relatively lesser female prisoners who were smokers (24.9\%) as compared to other international studies done on the prevalence of smoking amongst female prisoners.

While evaluating the use of smokeless tobacco consumption in United States, it was observed that annual consumption of smokeless tobacco has nearly tripled since the 1970s. ${ }^{[9]}$

Rajnarayan R. Tiwari et al, in their study about the use of smokeless tobacco in Nagpur, India, discussed that of the females, $12.6 \%$ were using smokeless tobacco. ${ }^{[10]}$

During our study, we found about $14.5 \%$ female prisoners were consuming smokeless tobacco. The prevalence of tobacco chewers in Pakistani female prisoners was high as compared to other countries like United States and India.Possible reason of increased intake of smokeless tobacco maybe due to the increased use of Paan in our cultural setting.

John S. et al, while assessing the diet of prisoners in England found that with the exception of some nutrients, prisoners have access to and are able to choose a nutritionally balanced diet. All prisons have attempted to make available menus that conform to the Balance of Good Health model. ${ }^{[11]}$

Williams P. et al, while evaluating the Prison foodservice in Australia found that the menus included adequate variety and met most nutritional standards, with the possible exception of fruit. ${ }^{[12]}$

In our study, we found a high lack of availability of fruits in the dietary schedules of the female prisoners of Pakistan. In comparison to other studies done internationally a nutritionally balanced diet was available for prisoners with possible exceptions of fruits in some cases, the Pakistani prisoners were lacking the availability of nutritionally balanced meals.

To assess the relationship between Obesity and use of excess fat in diet, Ram B. Singha et al, found the overall prevalence of central obesity among the total number of women was $55.0 \%$ and concluded that the overall prevalence of central obesity among the urban women of India has increased. Body mass index, sedentary lifestyle, and family history of excess intake of fat were significant risk factors for central obesity. ${ }^{[13]}$ 
Misra et al found that the prevalence of obesity and the metabolic syndrome has shown a rapid rise in developing countries in the past few decades and has led to increased risk ofCVDand consequent morbidity and mortality. The various factors responsible for increasing NCDs are rapid nutrition transition, rural-to-urban migration, increasingly sedentary occupations and lifestyle, and increased use of Ghee in the meals. ${ }^{14]}$

In our study, we found a similar association of increased BMI with increased consumption of Ghee in meals in the female prisoners of Pakistan. There was a positive correlation with increased BMI and consumption of Ghee specifically in Punjab province and KKB where Ghee is consumed more as compared to the province of Sindh where there is more Vegetable oil consumption resulting in lesser incidence of Obesity and increased BMI.

\section{Conclusion:}

The prevalence of risk factor of Non-communicable diseases in the female prisoners of Pakistan was found to be high. There was a higher incidence of smoking amongst the female prisoners than the normal female population of Pakistan. The dietary habits and less use of Fruits were seen in all the four prisons, thereby, increasing the risk of having Non-communicable diseases. There was a significant difference in the type of Oil consumption between the four jails of Pakistan. There was also a significant difference in the Body Mass Index of all the four jails. There was however no significant difference in the smoking status, use of smokeless tobacco and consumption of fruits in all the four prisons.

[1] Dawn Newspaper (April $7^{\text {th }}$ 2005)

\section{References}

[2] Boutayeb: The burden of non-communicable diseases in developing countries. Int. J. Equity Health. 2005;4:2.

[3] Maniyar M 2004. Women Criminals and their Life-Style, Kaveri Books, New Delhi

[4] WHO Global Strategy On Diet, Physical Activity \& Health (cited: www.who.org)

[5] Pakistan Human Rights Report, 2004

[6] Nasir K., Rehan N. Epidemiology of cigarette smoking in Pakistan. Addiction, 2006;96:1847-1854.

[7] Cropseya K., Gloria D.,Ladnerc T. Smoking among female prisoners: An ignored public health epidemic. Addictive Behaviours. $2004 \mathrm{Feb} ; 29(2): 425-431$.

[8] Tracy L. Durraha, Terry J. Rosenberg. Smoking among female arrestees: Prevalence of daily smoking and smoking cessation efforts. Addiction, 2004 Jul;29(5):1015-1019

[9] Office of the Inspector General: Spit Tobacco and Youth. Washington, DC, Department of Health and Human Services, OEI 06-9200500,1992 .

[10] Robertson P.B, Walsh M.M, Greene J.C. Oral effects of smokeless tobacco use, Advances in Dental Research 1997;11(3):307-312.

[11] John SA, Heather J, William G, Joachim S. The diet of prisoners in England. British Food Journal. 2009;109(3):216-232.

[12] Williams P, Walton K, Hannan-Jones M. Prison foodservice in Australia - systems, menus and inmate attitudes. Journal of Foodservice. 2009;20:167-180.

[13] Ram B. Singh, Ghosh S, BeegomR. Prevalence and Determinants of Central Obesity and Age-Specific Waist: Hip Ratio of People in Five Cities: The Indian Women's Health Study. European Journal of Cardiovascular Prevention \& Rehabilitation.1998 Apr:5:273-77.

[14] Misra Khurana: Obesity and the Metabolic Syndrome. J Clin Endocrinol Metab, November 2008,93(11):S9-S3.

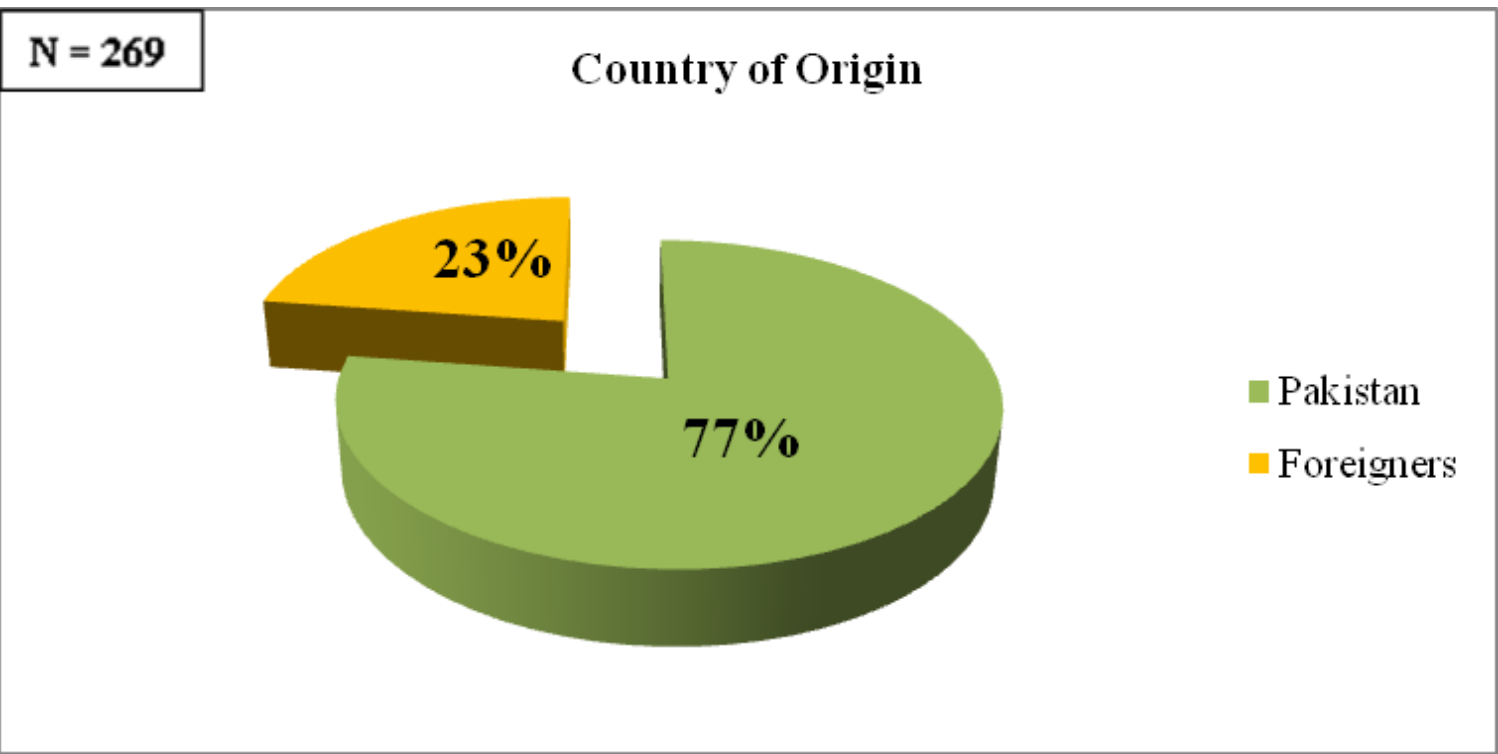

Figure I: Country of Origin of the Female Prisoners 


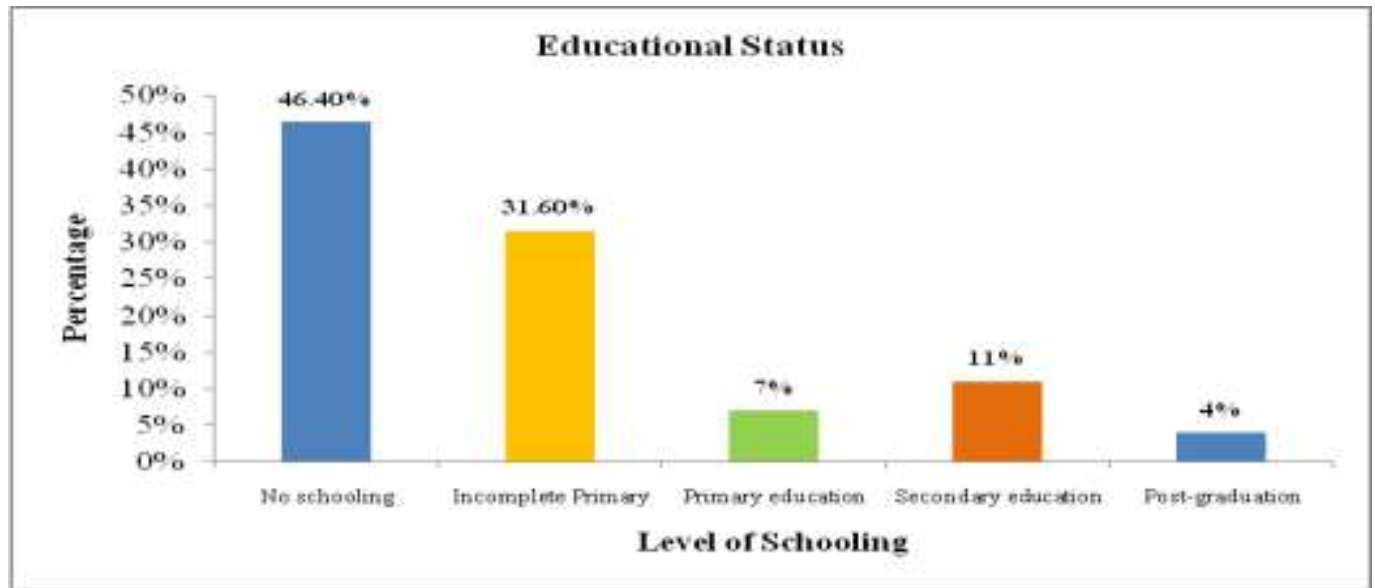

Figure II: Educational Status of Female Prisoners of Pakistan

Table I: Percentages of Female Prisoners with Various Risk factors for NCDs

\begin{tabular}{|c|c|}
\hline Variables & $\begin{array}{c}\text { Percentage of Female } \\
\text { Prisoners }\end{array}$ \\
\hline \multicolumn{2}{|l|}{ Number of Cigarettes Per day by current smokers (n=67) } \\
\hline $1-4$ cigarettes/day & $18 \%$ \\
\hline $5-10$ cigarettes/day & $29 \%$ \\
\hline $10-15$ cigarettes/day & $12 \%$ \\
\hline $16-20$ cigarettes/day & $16 \%$ \\
\hline$>20$ cigarettes/day & $5 \%$ \\
\hline \multicolumn{2}{|l|}{ Number of Fruit Servings Per Week } \\
\hline 0 servings/week & $75.4 \%$ \\
\hline 1-4 servings/week & $17.4 \%$ \\
\hline$>5$ servings/week & $7.2 \%$ \\
\hline \multicolumn{2}{|l|}{ Type of Oil Consumed } \\
\hline Vegetable Oil & $39 \%$ \\
\hline Ghee & $45 \%$ \\
\hline Not sure & $16 \%$ \\
\hline \multicolumn{2}{|l|}{ Body Mass Index (BMI) } \\
\hline Normal $(\mathrm{BMI}=19-24.9)$ & $46.5 \%$ \\
\hline Overweight $(\mathrm{BMI}=25-29.9)$ & $26.4 \%$ \\
\hline Obese $($ BMI $>30)$ & $27.73 \%$ \\
\hline
\end{tabular}

Table II: Comparative Analysis of various Risk factors of Non-Communicable diseases in Female Prisoners of the four Provinces of Pakistan

\begin{tabular}{|c|c|c|c|c|c|c|}
\hline Variables & Options & $\begin{array}{l}\text { Sindh } \\
\text { (n-114) }\end{array}$ & $\begin{array}{l}\text { Punjab } \\
(n=73)\end{array}$ & $\begin{array}{l}\text { Baluchistan } \\
(n=66)\end{array}$ & $\begin{array}{l}\text { KPK } \\
(n=16)\end{array}$ & $\begin{array}{l}\text { p- } \\
\text { Value* }\end{array}$ \\
\hline \multirow{2}{*}{ Smokers } & Yes & 30 & 19 & 18 & 5 & \multirow{2}{*}{0.97} \\
\hline & $\mathrm{No}$ & 84 & 54 & 48 & 11 & \\
\hline \multirow{2}{*}{$\begin{array}{l}\text { Smokeless } \\
\text { Tobacco }\end{array}$} & Yes & 15 & 18 & 12 & 4 & \multirow{2}{*}{0.21} \\
\hline & No & 99 & 55 & 54 & 12 & \\
\hline \multirow{3}{*}{ Oil Consumption } & Ghee & 10 & 59 & 39 & 11 & \multirow{3}{*}{$<0.00 *$} \\
\hline & Vegetable Oil & 79 & 9 & 16 & 2 & \\
\hline & Not Sure & 25 & 5 & 11 & 3 & \\
\hline \multirow{3}{*}{ Fruit Intake } & 0 servings/week & 89 & 44 & 48 & 9 & \multirow{3}{*}{0.17} \\
\hline & 1-4 servings/week & 20 & 21 & 14 & 4 & \\
\hline & >5servings/week & 5 & 8 & 4 & 3 & \\
\hline \multirow{3}{*}{ BMI } & Normal & 92 & 18 & 12 & 3 & \multirow{3}{*}{$<0.00 *$} \\
\hline & Overweight & 13 & 23 & 31 & 4 & \\
\hline & Obese & 9 & 32 & 23 & 9 & \\
\hline
\end{tabular}

*Values less than 0.05 are considered significant 